\title{
Research on Elastic Modulus of Gangue Concrete
}

\author{
Yanwen Chen ${ }^{1, a^{*}}$, Wanyang Niu ${ }^{1, b}$, Zhaoyang Ding ${ }^{1, c}$ \\ ${ }^{1}$ School of Materials science and Engineering, Shenyang Jianzhu University, China 110168 \\ achenyanwen0001@126.com, ${ }^{\mathrm{b}}$ niuwanyang@sjzu.edu.cn, ${ }^{\mathrm{c}}$ dingzhaoyang@sjzu.edu.cn
}

Keywords: gangue concrete, strength, elastic modulus, mathematical model

Abstract.The effect of gangue content on concrete strength and elastic modulus was studied in this paper and the mathematical model of modulus calculation was built up for gangue concrete. In the tests, concrete specimens in four strength grades of C20-C50 were prepared using equivalent replacement with substitution of 20\%-100\% gangue for gravel, and adjusted the concrete workability by admixture adding. The specimens were tested according to Standard GB/T50081, then the effect of gangue content on concrete strength and elastic modulus were studied. The mathematical model of strength, elastic modulus and apparent density of gangue concrete were built up.

The tests results showed that specific strength of $\mathrm{C} 20$ concrete changed little, the strength changed in the range of $\pm 2 \mathrm{MPa}$ with the variation of gangue content. The strength of $\mathrm{C} 30$ concrete did not changed obviously when gangue content was lower than $40 \%$, but the strength decreased significantly when the content was in the range of $40 \%-60 \%$ while the maximum strength reduced by $10.4 \%$; The strength tended to be steady when the content was greater than $60 \%$. The strength gradually decreased with the increase of gangue content for $\mathrm{C} 40-\mathrm{C} 50$ concrete and the strength decreased by $10 \%$ when the content increased to $40 \%$. The strengths of C40 and C50 concrete decreased by $17 \%$ and $27.5 \%$ respectively when the content ran up to $60 \%$ while the specific strength decreased in the range of $10 \%-20 \%$. On the whole, the concrete elastic modulus gradually decreased with the increase of the gangue content. The conclusions were: The gangue content could be unlimited for the concrete whose grade was equal to or lower than C20 because the content variation would not affect its strength and specific strength. The content would be strictly limited within $40 \%$ for C30 concrete because its strength decreased significantly if the content was greater than that. The content should be limited within 20\% for C40-50 concrete because the strength decreased by $5 \%$ when the content increased to $20 \%$. By studying the relationship between concrete strength and modulus, the mathematical model of elastic modulus calculation for gangue concrete was built up based on the test data and results, and the calculation formula was deduced: $\mathrm{E}_{\mathrm{c}}=$ $429.1 /\left(9.003+151.4 / f_{c}\right)$ or $\mathrm{E}_{\mathrm{c}}=6.036 \times 10^{-3} \times \rho \times f_{c}^{0.2388}$.

\section{Introduction}

Gangue is a sort of industrial waste produced in coal mining. It is used to be piled up in the open air year after year and that occupies large area of land, and what is more, causes the environment to be seriously polluted. Gangue has been widely used in concrete industry as a substituent for concrete aggregate. As a new aggregate, gangue has its own characteristics compared with gravel such as lower density, lower strength, stronger adsorption, better water-absorbency and so forth. Researchers have done a lot of work to study gangue concrete. Du Xiaomu, Song Yang studied and concluded that the particle size and substituted percentage of gangue aggregate should be increased if high-strength cement matrix was used since aggregate strength was lower than that of cement matrix and that could improve the concrete strength; But concrete strength could not be improved when low-strength cement matrix was used on the same conditions[1]. Guo Jinmin, Zhang Jinxi studied and proposed that the adding amount of gangue should be limited because the adding could cause some adverse effects on concrete durability[2,3]. Most of these researches and studies were mostly focused on the interactions among strength, durability and workability of gangue concrete but little on deformation of the concrete.

It is very important and significant to study the effect of gangue content on elastic modulus of gangue concrete because elastic modulus is one of the essential parameters in the calculations of 
concrete structural deformation checking, crack propagation and temperature stress of large-volumed concrete. Concrete elastic modulus is relative to the characteristics and the added amounts of aggregate[4]. The effect of variation of gangue content in mix proportion on concrete strength and elastic modulus was studied in the tests and discussed in this paper, then the mathematical formulas of elastic modulus calculation for gangue concrete were built up based on the test data and results and that laid the foundation for application and popularization of gangue concrete used as a structural material.

\section{Test Material and Test Method}

Test Material. P.O 42.5 cement, the observed flexural and compressive strength of $28 \mathrm{~d}$ were 8.4MPa and 48.6MPa respectively; admixture: high-efficient water reducer of carboxylic acids; additive: S95 fly ash, silica fume. The technical index of aggregate was shown in Table 1.

Table. 1 The Technical Index of Aggregate

\begin{tabular}{ccccccc}
\hline The material & $\begin{array}{c}\text { Diameter } \\
/ \mathrm{mm}\end{array}$ & $\begin{array}{c}\text { Bulk } \\
\text { density } \\
/ \mathrm{Kg} / \mathrm{m}^{3}\end{array}$ & $\begin{array}{c}\text { Density } \\
\mathrm{g} / \mathrm{cm}^{3}\end{array}$ & $\begin{array}{c}\text { Crushing } \\
\text { Valve } \\
\text { Index/\% }\end{array}$ & $\begin{array}{c}\text { Water } \\
\text { Absorption\% } \%\end{array}$ & $\begin{array}{c}\text { Fineness } \\
\text { Module }\end{array}$ \\
\hline crushed stone & $5-25$ & 1560 & 2.72 & 8.4 & 1.1 & \\
Gangue & $5-25$ & 1380 & 2.60 & 12.6 & 4.4 & 2.7 \\
sand & $0.15-4.75$ & 1520 & 2.70 & & 1.0 & 2.7 \\
\hline
\end{tabular}

Test method. Three methods were commonly used in concrete deformation measurement at home and abroad. They are the butterfly-typed extensometer method, the strain gauge method and the dial gauge method. The measurement result was more accurate using the strain gauge method[5]. The DH-3820 static strain testing system was used in the tests. The test specimen sizes were $150 \times 150 \times 300 \mathrm{~mm}$ and the strain gauge lengthes were $100 \mathrm{~mm}$. The strain gauges were affixed to two opposite sides of the test specimens. Then continuous loading was applied to the specimens along the axial direction. The axial deformation was measured under the load in the range of $0.5 \mathrm{MPa}$ to one-third compressive strength of concrete standard cube. Then concrete elastic modulus was calculated and MATLAB was used for data fitting.

\section{Analysis of the Test Results}

Testing Scheme. In the tests, concrete of grades C20-C50 was prepared by mass equivalent replacement of gravel with gangue. The substituted percentages of gravel for gangue were respectively $20 \%, 40 \%, 60 \%, 80 \%$ and $100 \%$ by mass. The concrete workability could be guaranteed by adjustment of admixture content, and the concrete slumps were within $160 \mathrm{~mm}-200 \mathrm{~mm}$. Then the compressive strength, elastic modulus of $28 \mathrm{~d}$ age concrete was measured. The mix proportion of concrete was shown in Table 2.

Table .2 The Mix Proportion of Concrete $\left(\mathrm{Kg} / \mathrm{m}^{3}\right)$

\begin{tabular}{ccccccccc}
\hline $\begin{array}{c}\text { Strength } \\
\text { Grade }\end{array}$ & $\begin{array}{l}\text { Water-Binder } \\
\text { Ratio }\end{array}$ & Cement & Fly & Water & Sand & $\begin{array}{c}\text { Silica } \\
\text { Fume }\end{array}$ & Gravel & $\begin{array}{l}\text { Chemical } \\
\text { Admixtures }\end{array}$ \\
\hline C20 & 0.5 & 280 & 80 & 180 & 763 & 0 & 1097 & 2.1 \\
C30 & 0.4 & 347 & 100 & 180 & 721 & 0 & 1082 & 2 \\
C40 & 0.35 & 412 & 80 & 170 & 698 & 0 & 1076 & 2.2 \\
C50 & 0.31 & 450 & 70 & 165 & 671 & 18 & 1067 & 2.5 \\
\hline
\end{tabular}

Effect of Gangue Content on Strength and Specific Strength of Concrete. The aggregate characteristics were one of the main factors which affected the concrete performance. Gangue's lower density, lower strength and higher water absorption could all have effect on concrete strength. The relation curve was drawn according to the test data and results in order to reveal the relationship among gangue content, concrete strength and specific strength which was shown in Figure 1 and Figure 2. 


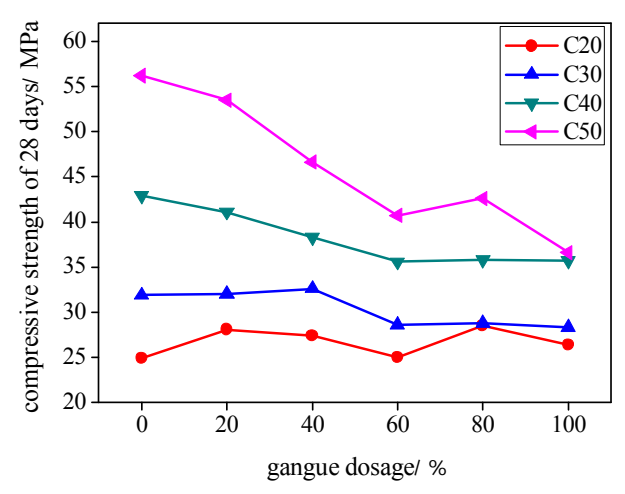

Figure.1 Effect of Gangue Content on Compressive Strength of 28d Concrete

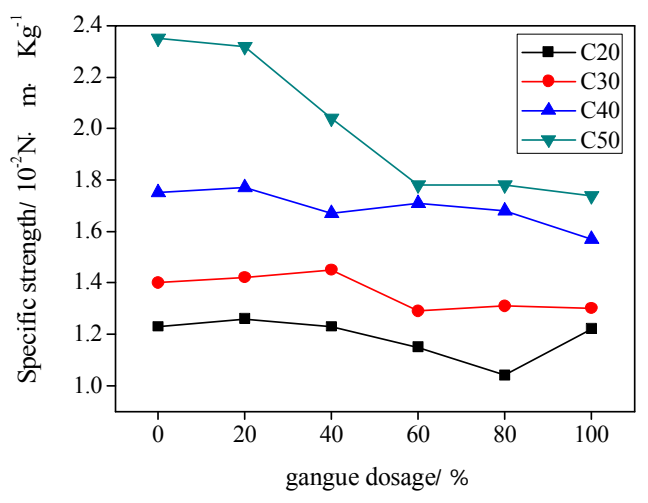

Figure.2 Effect of Gangue Content on Concrete Specific Strength

Some conclusions could be drawn by analyzing Figure 1 that the gangue content variation had little effect on the strength of C20 concrete. That was because the designed strength grade for C20 concrete was low and the requirement for raw material was not high, and using gangue as concrete aggregate could completely satisfy the performance requirement. That led the strength fluctuation to a little change. Besides, cement slurry could fill some of the pores in aggregate for gangue's higher porosity, the gangue aggregate was compacted and the strength was increased. That guaranteed the cement matrix strength and aggregate strength to coordinate with each other[6] and the strength of C20 concrete was unchanged or slightly increased. The strength changed a little for C30 concrete when gangue content was within $40 \%$. But the strength showed an obvious decreasing trend when the content increased to $60 \%$. At this stage, more than half of the total aggregate mass was depended on gangue mass and that led coarse aggregate strength could not match with cement matrix strength. The strength of partial gangue aggregate reached its limit when the bonding surface between cement slurry and aggregate was not damaged. The gangue aggregate could not resist any more external force and began to be damaged and that made concrete strength and bearing capacity decreased rapidly. This phenomenon could also be verified by the observation on the concrete damaged surface and it was significantly obvious for C40 and C50 concrete. The compressive strength of $28 \mathrm{~d}$ C40 and C50 concrete dropped by 5\%, 20\% when gangue content was up to $20 \%$ and $40 \%$ respectively. The strength of C50 concrete fell to $36.6 \mathrm{MPa}$ when the content was $100 \%$ and that was far below the designed strength. Therefore, the gangue content should be strictly limited in the production of $\mathrm{C} 30$ and higher grade concrete while it was unnecessary to limit that for lower-grade concrete.

Gangue had the characteristics of lower density and higher porosity compared with that of gravel. For C20 and C30 concrete, it could be known by analyzing Figure 2 that the volume fraction of aggregate increased while that of cement slurry decreased after the equivalent replacement of gravel with gangue. That was because gangue absorbed some of the cement slurry and its density increased while concrete strength changed little. Hence the specific strength of $\mathrm{C} 20$ and $\mathrm{C} 30$ concrete was fluctuated in the range of $\pm 0.2 \times 10^{-2} \mathrm{~N} \cdot \mathrm{m} / \mathrm{kg}$. By contrast, the specific strength of C40 and C50 concrete gradually decreased with the increase of the gangue content.

Effect of Gangue Content on Concrete Elastic Modulus. The aggregate percentage in concrete was $60 \% \sim 70 \%$ of the whole mixture by volume. Aggregate's characteristics such as shape, lithology, elastic modulus, surface structure had some effect on concrete elastic modulus in different extent[7]. The strength of the gangue aggregate used in the tests was lower and its performance was worse compared with ordinary gravel because of its incompact surface structure, higher water absorption and some contained impurities. This showed that the characteristics of gangue aggregate must have great effect on concrete's elastic modulus. The relation curve of the effect of gangue content on concrete elastic modulus was drawn according to the test data and results and shown in Figure 3. 


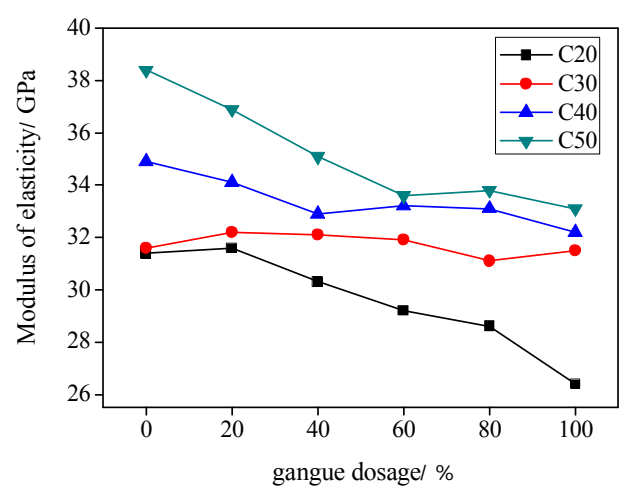

Figure. 3 Effect of Gangue Content on Concrete Elastic Modulus

The test data showed that the elastic modulus fluctuated in the range of $\pm 1 \mathrm{GPa}$ for $\mathrm{C} 20$ concrete when gangue content increased from 0 to $100 \%$. This suggested that gangue aggregate contained some micropores. They could buffer or reduce impact and make concrete deformed little[7,8]. The elastic modulus of $\mathrm{C} 30$ concrete presented a gradually decreasing tend with the increase of the gangue content, and the modulus reduced by $3.5 \%$ when gangue content reached $100 \%$. The elastic modulus of C40 and C50 concrete changed obviously. The significant decrease began when the content was within $40 \%-60 \%$ and the maximum decrease could be $7.5 \%$. The modulus decreased by $12 \%$ when gangue's substituted percentage was $100 \%$. It could be known by analyzing the test results that aggregate strength played a certain role in the decision of concrete elastic modulus. High-performanced aggregate was unnecessary to be used to maintain the concrete strength because the strength of C30 and lower grade concrete was not high enough. The cement paste and the gangue's deformation caused by external force could cause the synergistic effect which could share the forced deformation increase for $\mathrm{C} 30$ and lower grade concrete. The elastic modulus of C40 and higher grade concrete decreased obviously when the substituted percentage increased to $40 \%$. The aggregate deformation rapidly increased while the paste deformed little and they could not work collaboratively when the load exerted on concrete continuously increased. This showed the aggregate strength could not meet the needs of the development of concrete strength and the concrete supporting framework lost its workability[8,9]. Therefore, the increase of the gangue content had an obviously negative effect on elastic modulus for $\mathrm{C} 40$ and higher grade concrete. Gangue began to play a decisive role in the decision of concrete performance with the increase of its substituted percentage in total aggregate. Thus, the gangue content should be appropriately determined in practical application according to different concrete grades in order not to affect the normal use for the reduced elastic modulus[10].

The Relationship among Strength, Elastic Modulus and Apparent Density of Gangue Concrete. In elastic modulus measurement, the high precision, long test cycle and many related factors led to the results having greater discreteness[11]. That was why concrete elastic modulus was usually obtained by deducing from theoretic mathematical model rather than by measurement. Meanwhile, concrete was composed of many kinds of material, and their composition, properties and molding condition could all have great effects on concrete performance. So the established formulas of elastic modulus calculation were greatly different from each other[12].

In China, the empirical formula for elastic modulus calculation was given in GB50010: 《Code for design of concrete structures》. It was:

$$
\mathrm{E}_{\mathrm{C}}=\frac{10^{5}}{2.2+\frac{34.7}{f}}
$$

In the formula, $\mathrm{E}_{\mathrm{C}}$,represented the elasticity modulus (MPa); $\mathrm{f}^{\prime}$, the concrete strength (MPa). Another formula which included concrete strength, elastic modulus and apparent density was given by American AASHTO in 13-ACI318M-05. It was: 


$$
\mathrm{E}_{\mathrm{C}}=0.0439(\omega) 1.5 \sqrt{f_{c}}
$$

In the formula, $\mathrm{E}_{\mathrm{C}}$, represented the elasticity modulus $(\mathrm{MPa}) ; \omega$, the apparent density of concrete $\left(\mathrm{Kg} / \mathrm{m}^{3}\right)$; $\mathrm{fc}^{\prime}$, the concrete strength $(\mathrm{MPa})$.

These formulas only fitted elastic modulus calculation for ordinary concrete. The MATLAB curve fitting toolbox was used in the paper in optimum fitting by the least square method. Formulas (3) and (4) which showed the relationship between strength and elastic modulus for gangue concrete were built up by using the square of minimum error and to find the best function matching for testing data. The fitting curves were shown in Figure 4. Formulas (5) and (6) which showed the relationship between elastic modulus and apparent density for gangue concrete were built up by using the functional relation of concrete strength and density. The mathematical models and the residual analyses were shown in Figure 5 and Figure 6.

$$
\begin{aligned}
& \text { Equation3: } \mathrm{E}_{\mathrm{C}}=429.1 /\left(9.003+151.4 / f_{c}\right) \\
& \text { Equation4: } \mathrm{E}_{\mathrm{C}}=5.379 \sqrt{f_{c}} \\
& \text { Equation5: } \mathrm{E}_{\mathrm{C}}=6.036 \times 10^{-3} \times \rho \times f_{c}^{0.2388} \\
& \text { Equation6: } \mathrm{E}_{\mathrm{C}}=4.918 \times 10^{-5} \times \rho^{1.5} \times \sqrt{f_{c}}
\end{aligned}
$$

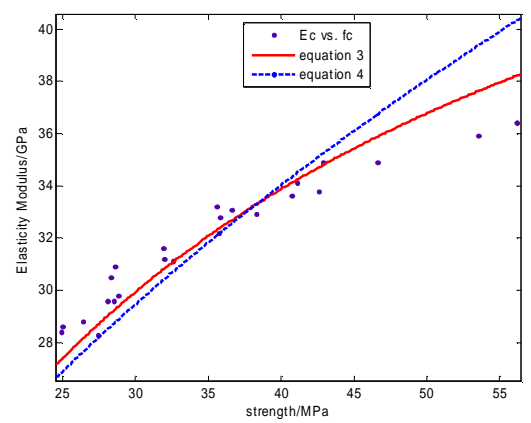

Figure .4 Relationship Analysis of Strength and Elastic Modulus of Gangue Concrete

It could be clearly seen from the fitting curves in Figure 4 that less discrete and better fitting effect were obtained using Equation 3 instead of Equation 4. So Equation 3 should be adopted in elastic modulus calculation for gangue concrete according to concrete strength reckoning.

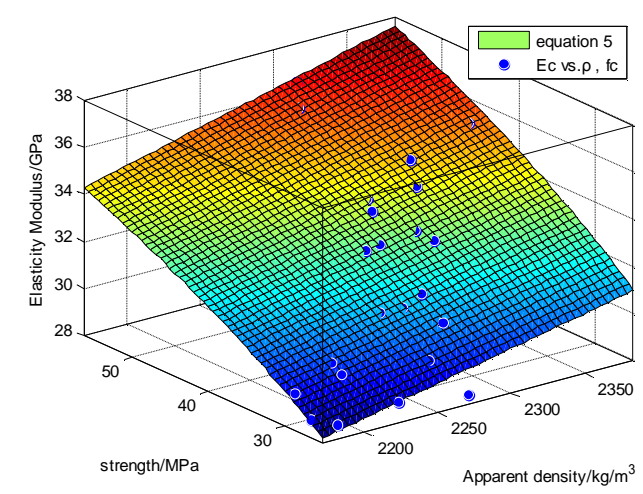

(a) The Mathematical Model for Strength,

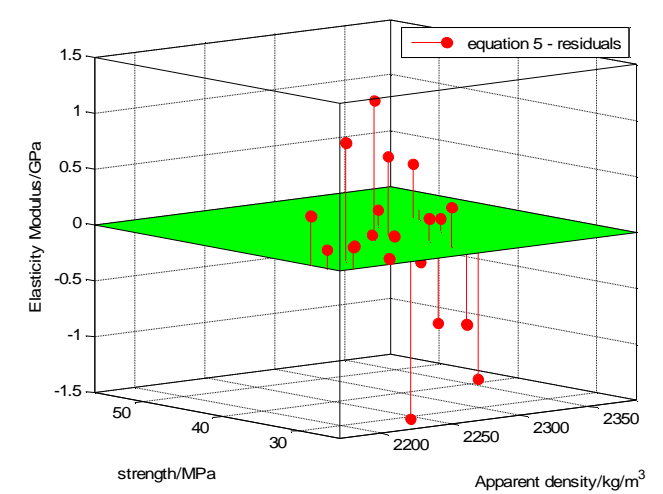

(b) The Residual Analysis Elastic Modulus and Apparent Density

Figure. 5 The Mathematical Model for Strength, Elastic Modulus, Apparent Density \& The Residual Analysis(for Equation 5) 


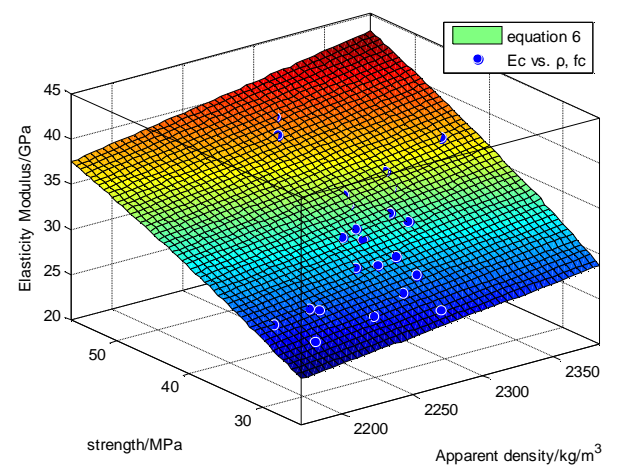

(a) The Mathematical Model for Strength, Elastic Modulus and Apparent Density

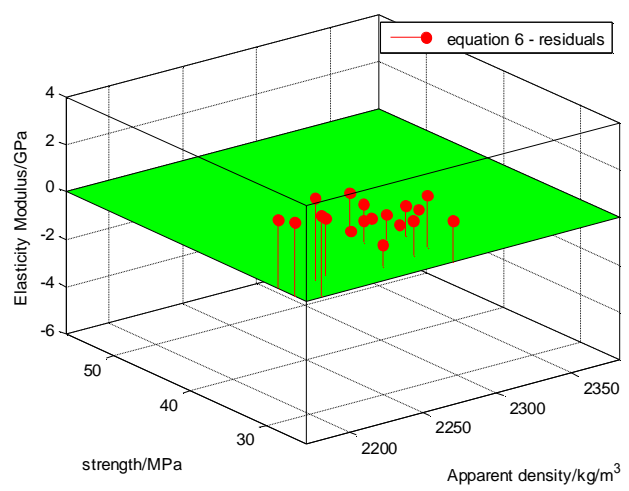

(b) The Residual Analysis

Figure .6 The Mathematical Model for Strength, Elastic Modulus, Apparent Density \& The Residual Analysis(for Equation 6)

For Equation 5 and its relative model, the index coefficient R2's value of regression analysis was greater than that of Equation 6 by analyzing Figure 5 and Figure 6. Furthermore, great residual only existed in very few data in Figure 5 by analyzing residual figures of two models, and the data basically fitted well in and near the function plane in Figure 5. By contrast, the residual in Figure 6 was greater and the data distributed on the same side of the plane. Thus, Equation 5 should be adopted and used for its better fitting effect to calculate and explain the relationship among strength, elastic modulus and apparent density.

\section{Conclusions}

In the series of mix proportion for $\mathrm{C} 20-\mathrm{C} 50$ concrete, the coarse aggregate of the original proportion was equivalently replaced with gangue aggregate of $20 \%$ to $100 \%$. The change laws of concrete strength, specific strength and elastic modulus with the increase of the gangue content were studied and discussed in the paper. Finally, the mathematical model of elastic modulus calculation for gangue concrete was built up.

The gangue content variation had little effect on strength and specific strength for C20 concrete and could only make the elastic modulus fluctuated in the range of $\pm 1 \mathrm{GPa}$. So it was unnecessary to limit the gangue content in the preparation of $\mathrm{C} 20$ concrete and below that grade.

The strength gradually decreased when gangue content was lower than $40 \%$ for C30 concrete. The strength decreased by $10.4 \%$ which was the lowest when the content was $60 \%$. Then elastic modulus also gradually decreased with the increase of the gangue content, and the modulus decreased by $1.1 \mathrm{GPa}$ when the content increased to $80 \%$. Therefore, it was suggested that gangue content should be limited lower than $40 \%$ for C30 concrete. 
Gangue content could significantly affect the strength for C40-C50 concrete and the strength gradually decreased with the increase of the content. The elastic modulus and strength decreased by $5 \%$ and greater than $10 \%$ respectively when the content was up to $40 \%$. The strength and the specific strength would decrease by $59 \%$ and $10-20 \%$ respectively for C50 concrete when all the gravel was completely replaced by gangue. Hence, the gangue content should not exceed $20 \%$ for C40-C50 concrete.

The mathematical model was built up based on the results of strength a;nd elastic modulus tests and the calculation formula was deduced: $\mathrm{E}_{\mathrm{c}}=429.1 /\left(9.003+151.4 / f_{c}\right)$; The formula based on the results of strength, elastic modulus and apparent density tests was obtained: $\mathrm{E}_{\mathrm{C}}=$ $6.036 \times 10^{-3} \times \rho \times f_{c}^{0.2388}$.

\section{Acknowledgements}

The financial help of the national science and technology supportment Project program of china (Project No., 2012BAJ17B01) is gratefully acknowledged.

\section{References}

[1] Duan xiao-mu, Xia Junwen, 2014. Experimental Research on the influence of coal gangue Aggregate behavior on the mechanical properties of concrete. Industrial Construction, 44(3): 114-118.

[2] GUO Jinmin, ZHU Lingli, 2011. Orthogonal experiment on durability of coal gangue concrete .Journal of Liaoning Technical University(Natural Science ), 30(4): 565-570.

[3] ZHANG Jinxi, CHEN Weilin, 2011. Investigation on Durability of Coal Gangue Aggregate Concrete . Journal of BEIJING University of Technology, 37(1):114-125.

[4] WANG Yuan-feng, LIANG Ya-ping, 2004. Study on Modulus of Elasticity and Poisson Ratio of High Performance Concrete .Journal of northern JIAOTONG university, 28(2): 5-16.

[5] ZHANG Jing nan,2003. Experimental study on elastic modulus of performance concrete containing fly ash. Contrete,(11): 43-45 . [9] GU Zhangchuan,2011. Experimental research of concrete elastic moudulus predict. Concrete, (5): 30-32.

[6] Lei Xiuling, LI Yanping,2009. Test method and influence factor modulus of plastic concrete . Water Resources and Hydropower of Northeast,(7): 68-72.

[7] Wang Fazhou,2005. Research on the influence of substitution of normal aggregate light weight aggregate on the strength and elastic modulus of concrete . Journal of HENAN of polytechnic University, 24 (2): 136-139.

[8] ZHENG Jianjun*, LV Jianping, WU Zhimin,2008. Prediction of the elastic modulus of concrete with inhomogeneous . Acta Materiae Compositae Sinica, 25(5): 141-146.

[9] GU Zhangchuan,2011. Experimental research of concrete elastic moudulus predict. Concrete, (5): 30-32.

[10] LI Yang,2013. Research on Calculating Method for Elastic Modulus of Plastic Concrete . J of China Three Gorges Univ ( Natural Sciences), 35(4:)74-76. 
[11] HE Sheng-dong,2010. Experimental research on elastic modulus of manufactured sand concrete with different replacement ratios. Journal of Guangxi University Nat Sci Ed, 35(8) : 698-701.

[12] HAN Yudong,2013. Effect of volume fraction of coarse aggregate on elastic modulus and compressive strength of concrete . Journal of HAERBIN institute of technology, 45(4): 84-91. 